\title{
UM ENSAIO METODOLÓGICO SOBRE A QUALIDADE DE VIDA NO DISTRITO DE CACHOEIRINHA, ZONA NORTE DA CIDADE DE SÃO PAULO - SP
}

\author{
Marília Araújo Roggero ${ }^{1}$ \\ Ailton Luchiari²
}

\begin{abstract}
Resumo: A qualidade de vida urbana tem sido estudada pelas mais diversas áreas do conhecimento e é uma temática complexa. O tema qualidade de vida envolve questões multidisciplinares apresentadas por meio de perspectivas diferenciadas, de acordo com a relevância do momento histórico, das condições sociais, bem como da ideologia dominante a partir dos objetivos propostos. Isso posto, a abordagem adotada no presente estudo está focada na satisfação das necessidades básicas da população, de modo a garantir o pleno desenvolvimento físico, mental e social. Para isso, foram abordadas quatro dimensões: condições de saneamento, situação socioeconômica e demografia, por meio da utilização dos dados censitários (IBGE, 2000) e as zonas residenciais homogêneas, por meio de técnicas de interpretação de imagens de satélite com alta resolução espacial. Para a espacialização e processamento dos dados quantitativos e qualitativos foram utilizadas técnicas de Geoprocessamento, por meio do uso de um Sistema de Informação Geográfica e técnicas estatísticas multivariadas (análise fatorial e cluster análise), que garantiram a distribuição espacial dos dados levantados. A partir dos resultados alcançados por meio dessas técnicas, foi possível elaborar o mapa síntese da qualidade de vida do distrito da Cachoeirinha, zona norte da cidade de São Paulo.
\end{abstract}

Palavras-Chave: Qualidade de vida; Sistemas de informações geográficas; Estatística multivariada; Zonas Residenciais homogêneas; Geoprocessamento.

\section{A METHODOLOGICAL ESSAY ABOUT QUALITY OF LIFE IN THE DISTRICT OF CACHOEIRINHA, NORTH ZONE OF SÃO PAULO - SP.}

\begin{abstract}
The quality of urban life has been studied in various areas of academic specialization and is a complex theme. The subject's quality of life involves multi-disciplinary questions presented with different perspectives, according to the relevance of the historical moment, social conditions, as well as the dominant ideology shaping the objectives in question. The approach adopted in the present study is focused on the satisfaction of the basics needs of the population, in order to guarantee complete physical, mental and social development. For this, four dimensions were considered: conditions of sanitation; the socioeconomic situation and demography; using data of the last demographic Census in 2000 (IBGE, 2000); and homogeneous residential zones, by means of technical interpretation of satellite images with high spatial resolution. For the spatial results and processing of
\end{abstract}

\footnotetext{
${ }^{1}$ Programa de Pós-Graduação em Geografia Física da FFLCH USP - E-mail: marilia.roggero@usp.br

${ }^{2}$ Departamento de Geografia FFLCH USP - E-mail: aluchiar@usp.br

DOI: 10.7154/RDG.2011.0022.0005
} 
quantitative and qualitative data, techniques of Geoprocessing had been used, using Geographic Information System and multivariate statistical techniques (factor analysis and cluster analysis), which had guaranteed the spatial distribution of the listed data. From the results obtained with these techniques, it was possible to elaborate the map synthesis of the quality of life of Cachoeirinha District, northern zone of São Paulo, Brazil.

Key Words: Quality of life; Geographic Information System; Multivariate statistics; Homogeneous Residential Zones; Geoprocessing.

\section{INTRODUÇÃO}

O espaço urbano é o local onde grupos sociais vivem, se reproduzem e reproduzem-no, ou seja, um espaço dinâmico em constante transformação. Deste modo, as formas criadas no interior urbano condizem com as funções que necessitam serem realizadas nas mesmas como moradias, serviços, indústrias e comércio. É certo também que através da dinâmica urbana estas formas sofrem diversas transformações em seu uso, isto é, moradias viram escritórios, indústrias transformam-se em centro culturais e assim por diante. A identificação das formas urbanas através do agrupamento pode definir zonas dentro das cidades tais como: zonas residenciais, comerciais e industriais.

As modificações na metrópole em geral geram transformações no tecido urbano que podem ser representados através dos mapas. De acordo com Luchiari (2005), os geógrafos têm preocupações acerca destas representações que estão diretamente relacionadas com a distribuição dos fenômenos que ocorrem na superfície da Terra.

O Sensoriamento Remoto e suas técnicas vêm constituindo um instrumento imprescindível para os profissionais que como o geógrafo estuda o espaço urbano. A interação entre sistemas de Informações geográficas (SIG) e sensoriamento remoto faz-se também indispensável, pois hoje se exige a atualização periódica de bases de dados que representem a situação atual. Dados básicos para o planejamento precisam ser atualizados constantemente e na medida do possível com qualidade na resolução. Isso significa que um mapa digital hoje se torna desatualizado se o mesmo não representar uma junção da situação presente, fundida com uma base de dados também atualizada.

As bordas urbanas conforme a região da área de estudo, que assim é considerada, devido à barreira física representada pela Serra da Cantareira e sua área de preservação, apresentam mais do que qualquer outra parte das metrópoles uma dinâmica de crescimento populacional e expansão urbana diversificadas. O aumento da segregação residencial em São 
Paulo está diretamente relacionada a questões de fronteira urbana, denominada por Torres (2005), como uma categoria de análise das ciências sociais não inédita, principalmente na área ligada ao planejamento urbano. $O$ autor questiona o fato de não designarmos essas áreas apenas como periferias ou áreas periurbanas, e que embora na cidade de São Paulo, sejam áreas predominantemente externas, ou seja, que extrapolam os limites da região metropolitana de São Paulo, entende-se neste estudo que a região da Cachoeirinha inserese diretamente em área de fronteira urbana, inserida no município de São Paulo, mas que encontra sua limitação em expandi-la diretamente relacionada à barreira física representada pelo Parque Estadual da Cantareira.

\section{Área de Estudo}

O Distrito de Cachoeirinha está localizado na zona norte da cidade de São Paulo e faz limite com o Parque Estadual da Serra da Cantareira.

Figura 1

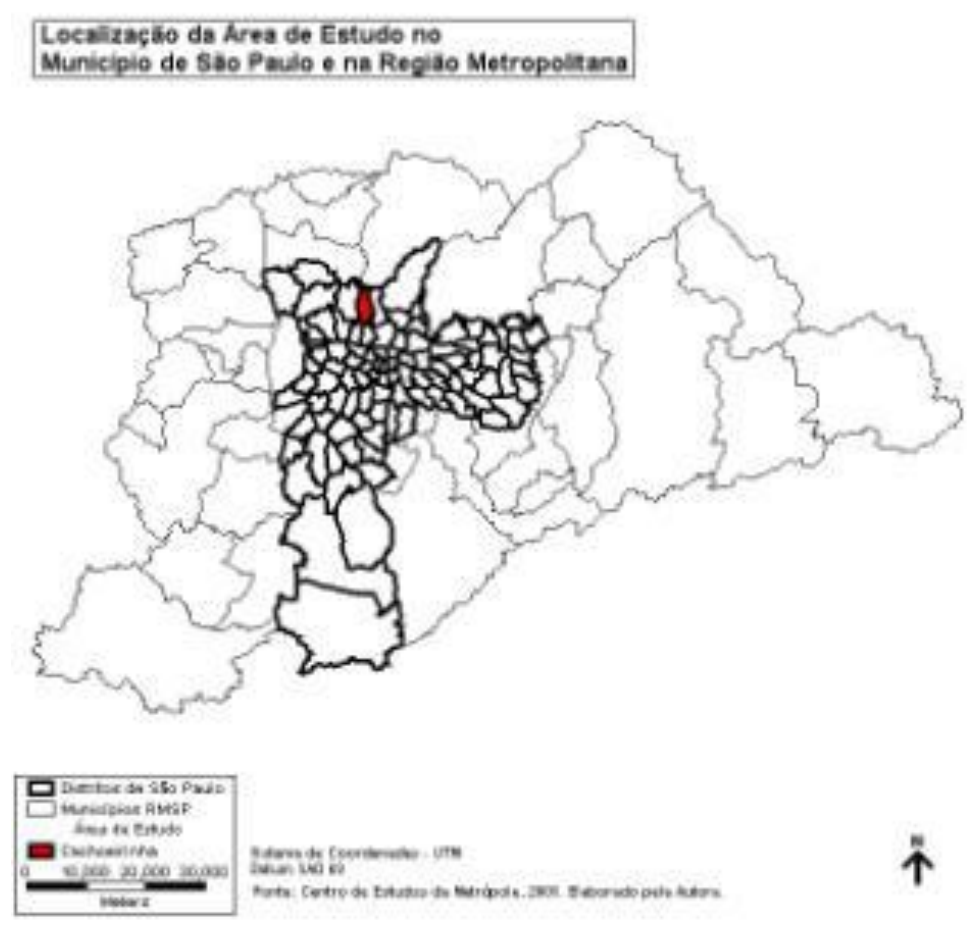

O recorte espacial dado pelo limite político e administrativo do distrito da Cachoeirinha se deu devido ao fato da sua localização, no limite urbano da cidade ao norte representada pela Serra da Cantareira e devido à importância que unidade de análise distrito representa em nível municipal para o planejamento, de acordo com a Lei Orgânica do Município de São 
Paulo de 1991 (LO - MSP, 1991 apud in NUCCI, 2001), que estabelece a divisão distrital como definidora de unidades de planejamento.

\section{FUNDAMENTAÇÃO TEÓRICA E METODOLÓGICA}

A metodologia desenvolvida na presente pesquisa baseou-se na linha de pesquisa da Geografia Teorética, essa linha de pesquisa em Geografia é também conhecida como Geografia Quantitativa e está inserida no contexto da Nova Geografia.

Segundo Carlos (1994), a preocupação do espaço permeia e sempre permeou os estudos geográficos, mas nem sempre o espaço foi conceituado e estudado do mesmo modo pelos geógrafos. Estas concepções diferentes, segundo a autora, por vezes desemboca na noção de espaço como palco da atividade humana, algo comum no movimento da Nova Geografia. Nesse sentido, a preocupação com a fundamentação teórica - metodológica precisa se impor. Os estudos, principalmente os urbanos na Geografia, certamente já ultrapassaram a barreira monográfica da descrição, o espaço geográfico não é mais visto como algo inerte, eterno ou natural ele é um produto concreto das relações sociais historicamente determinadas.

Ao tentarmos construir indicadores para analisar um fenômeno que se concretiza no espaço geográfico, tal como o da qualidade de vida urbana, a dimensão do espaço como palco da vida humana não é pertinente. Nosso olhar geográfico, capturado por meio de interpretação de imagens, análise de dados, nos permite compreender o modo como a sociedade organiza seu espaço, sua vida e como estes se apresentam de maneira contraditória, sem perder de vista a relação homem-meio, tendo o primeiro como o produtor desse espaço.

Na Geografia, as raízes da quantificação segundo Chilson (1975, apud in Santos, 2002) não estão apoiadas apenas na estatística moderna, mas sim, na ciência cartográfica. Após a Segunda Guerra Mundial as ciências sofreram transformações e conseqüentemente, a Geografia também sofreu esse impacto.

A emergência de novas discussões e reflexões oriundas das mais variadas disciplinas e dos mais diversos discursos, impulsionou a origem de uma Nova Geografia, manifestada principalmente por meio da quantificação. Foi nos anos 70 que se iniciou a propagação da Nova Geografia no Brasil a partir de instituições como IBGE, Universidade Federal do Rio de Janeiro e Universidade Paulista Júlio de Mesquita Filho - Rio Claro (UNESP). O IBGE, em 
1972, publica um texto onde enfatiza a importância da formulação de hipóteses e do embasamento estatístico para validá-las por meio de um conjunto de técnicas computacionais.

Geralmente quando o geógrafo se propõe a trabalhar com dados, o volume a ser considerado de informação geralmente é grande, logo então aparece a necessidade de manipulação, compreensão dos dados e a transformação da massa de informação, por meios propiciados pela análise quantitativa.

A quantificação é uma diretriz metodológica que permite não só a explicação de um problema em questão como também o enriquecimento teórico-conceitual e conseqüentemente generalizações em etapas posteriores do trabalho. A quantificação é um meio e não um fim para chegar a conclusões.

Câmara et al. (2000), relata que a base da Geografia Quantitativa é a busca da aplicação do método hipotético - dedutivo que caracteriza as ciências naturais nos estudos geográficos. A lógica desse método é a de que existe uma realidade externa à nossa existência e que esta pode ser capturada de forma aproximada através dos princípios da lógica e da matemática.

A Geografia sob a ótica da escola teorética, propõe a construção de modelos a serem utilizados nas análises geográficas. Esses modelos devem ser validados e verificados com levantamentos realizados em campo e a partir de técnicas estatísticas; isso posto, a escola da Geografia Quantitativa demonstra grande ênfase em técnicas de análise espacial e Geoestatística (Bailey and Gattrel 1995 apud in Câmara, 2000).

Harvey (1969) é quem detalha de forma elucidativa o método hipotético-dedutivo abordado por Câmara et. al (2000), o autor exemplifica o método como sendo um sistema que captura como a realidade se estrutura, para depois capturar imagens dessa realidade e posteriormente identificar modelos. O consenso básico é a elaboração de um critério que pode ser desenvolvido com respeito à explicação em Geografia, tendo em vista analisar as várias maneiras que nós podemos assegurar uma explicação consistente dessa ciência. Para o autor é também tarefa da Geografia considerar a aplicação de um critério para explicar um fenômeno geográfico.

Apesar das diversas abordagens e diversos significados que o conceito de qualidade de vida pode assumir em sua mensuração, os trabalhos citados e suas respectivas metodologias 
utilizam preponderantemente dados que dizem respeito a aspectos objetivos e coletivos da sociedade.

Seria muito mais complexo trabalhar com questões relacionadas às satisfações pessoais, que fugiria do escopo do presente trabalho. Uma série de fatores influenciou na escolha das variáveis para compor os indicadores que culminaram na síntese da qualidade de vida, tais como, facilidade de acesso aos dados, escala de estudo, qualidade dos dados, padronização entre outros.

A tabela a seguir demonstra diversas metodologias que foram utilizadas para fins de mapeamento da qualidade de vida, abaixo da tabela segue o dicionário das variáveis, pois se cada variável fosse expressa nela sua visualização ficaria comprometida. A dimensão renda é utilizada como indicador em todos os estudos expostos, os autores em destaque foram pesquisados e utilizados como referência para a elaboração deste estudo.

Com relação às metodologias apresentadas acima, Morato (2004) atribuiu pesos diferentes para as variáveis utlizadas, algo que não se pretendeu no presente estudo, pois se considerou todas as variáveis de extrema importância para o mapa índice final. Sendo decidido por meio de análise multivariada, quais seriam viáveis para o estudo.

Outro fator que pode influenciar nos resultados obtidos por meio da utilização dos dados censitários, é o fato de se ter utillizado ou não apenas os domicílios permanentes considerados no censo demográfico. Pois, torna-se bastante complicado o uso de variáveis que podem ser temporárias e não refletirem, desta forma, a situação demográfica da unidade de análise escolhida, no caso o setor censitário.

No caso do ISsa - SEADE (índice socioambiental) o índice contou com os dados oriundos de bases vetoriais, sendo os setores censitários imputados com os dados do IPVS (índice paulista de vulnerabilidade social) e informações do Atlas Ambiental do Município de São Paulo.

O presente estudo contou com dados provenientes dos setores censitários 2000 e dados e de informações extraídas de imagens raster, transformadas em dados vetoriais por meio da fotointerpretação e posterior classificação das zonas residenciais homogêneas. No presente estudo também foram selecionadas variáveis que aliassem a qualidade ambiental à situação socioeconômica e a infraestrutura urbana. Essa seleção foi baseada nos critérios das necessidades básicas, que corresponde ao mínimo dos serviços e condições ambientais para que a população tenha uma vida saudável. 
Tabela 1: Metodologias e seus respectivos indicadores voltados ao mapeamento da Qualidade de Vida

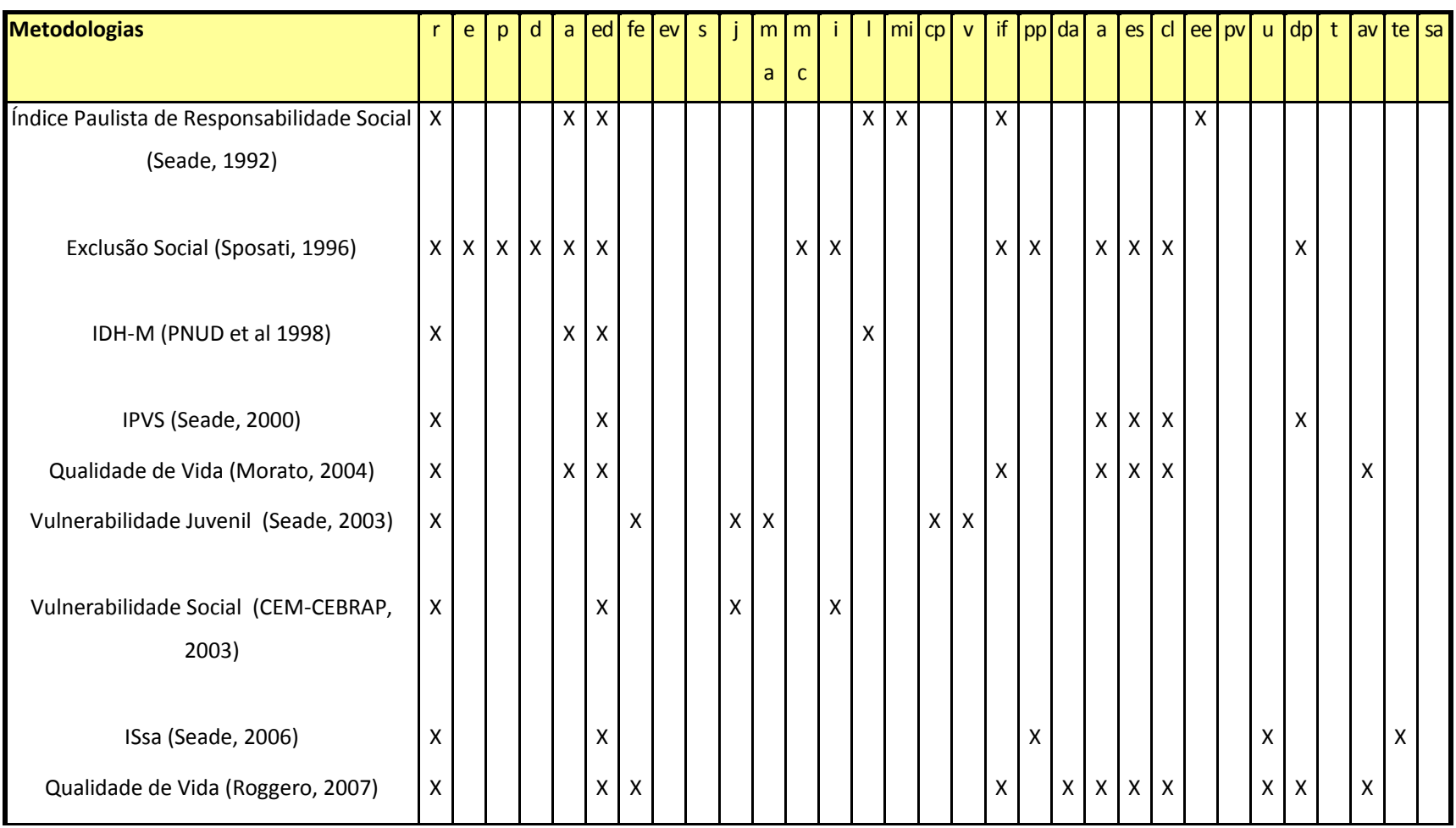

Legenda: r: renda; e: emprego; p: pobreza; d: desigualdade social; a: alfabetização; ed: escolaridade; fe: freqüência à escola; ev: evasão escolar; s: saúde; j: presença de jovens; ma: mães adolescentes; mc: mulheres chefes de família; i: presença de idosos; I: longevidade; mi: mortalidade infantil; cp: crescimento populacional; v: violência; if: infra-estrutura urbana; pp: propriedade domiciliar; da: domicílios alugados; a: abastecimento de água; es: destino do esgoto; cl: coleta de lixo; ee: energia elétrica; pv: pavimentação; u: classe de uso da terra nas áreas vizinhas; dp: densidade da população; t: tamanho da residência; av: áreas verdes; te: temperatura; sa: grau de satisfação da população

Fonte: LUCHIARI, KAWAKUBO, MORATO, MARTINES e FERREIRA A. \& F. S. \& R. G. \& M. R. \& R. V Mapeamento da Qualidade de vida Urbana no Município de Osasco/SP. Artigo apresentado no III Encontro da Associação Nacional de Pós Graduação e Pesquisa em Ambiente e Sociedade - Maio, 2006. Adaptado pela autora.

Apesar desse enfoque, estabelecer incentivos para se atingir o pleno desenvolvimento físico, mental e social, essa linha de pensamento deixa imprecisões a respeito de quais são essas necessidades e de como elas podem variar individualmente.

Na tabela a seguir encontram-se as variáveis pré-selecionadas do Censo Demográfico 2000, IBGE para a construção do mapa síntese da qualidade de vida.

A construção desses indicadores foi baseada outros estudos realizados e como o IPVS (Seade, 2000) e Vulnerabilidade Social (Cem-Cebrap, 2003). Essa seleção permite a identificação e utilização de indicadores já consagrados em outras pesquisas, minimizando deste modo às arbitrariedades. 
Tabela 2: Indicadores construídos a partir de variáveis do censo demográfico.

\begin{tabular}{|c|c|}
\hline $\begin{array}{c}\text { condições } \\
\text { de Habitação } \\
\text { (Porcentagem) }\end{array}$ & $\begin{array}{l}\text { Domicílios particulares permanentes } \\
\text { Domicílios particulares permanentes - tipo - cômodo } \\
\text { Domicílios particulares permanentes - condição de ocupação - próprio -quitado } \\
\text { Domicílios particulares permanentes - condição de ocupação - alugado } \\
\text { Domicílios particulares permanentes - sem banheiro ou sanitário }\end{array}$ \\
\hline $\begin{array}{c}\text { condições } \\
\text { de Saneamento } \\
\text { (Porcentagem) }\end{array}$ & $\begin{array}{l}\text { Domicílios particulares permanentes - abastecimento de água - rede geral } \\
\text { Domicílios particulares permanentes - abastecimento de água - rede geral - } \\
\text { canalizada em pelo menos um cômodo } \\
\text { Domicílios particulares permanentes - com banheiro ou sanitário - esgotamento } \\
\text { sanitário - } \\
\text { rede geral de esgoto ou pluvial } \\
\text { Domicílios particulares permanentes - destino do lixo - coletado por serviço de } \\
\text { limpeza }\end{array}$ \\
\hline $\begin{array}{c}\text { Renda } \\
\text { (Em Salários } \\
\text { Mínimos) }\end{array}$ & $\begin{array}{l}\text { Pessoas responsáveis pelos domicílios particulares permanentes } \\
\text { Rendimento nominal mensal - pessoas responsáveis pelos domicílios particulares } \\
\text { permanentes } \\
\text { Pessoas responsáveis pelos domicílios particulares permanentes - } \\
\text { rendimento nominal mensal - até } 1 / 2 \text { salário mínimo } \\
\text { Pessoas responsáveis pelos domicílios particulares permanentes - } \\
\text { rendimento nominal mensal - mais de } 1 \frac{1}{2} \text { a } 1 \text { salário mínimo } \\
\text { Pessoas responsáveis pelos domicílios particulares permanentes - } \\
\text { rendimento nominal mensal - mais de } 1 \text { a } 2 \text { salários mínimos } \\
\text { Pessoas responsáveis pelos domicílios particulares permanentes - } \\
\text { rendimento nominal mensal - mais de } 2 \text { a } 3 \text { salários mínimos }\end{array}$ \\
\hline $\begin{array}{l}\text { Características } \\
\text { Demográficas } \\
\text { (Porcentagem) }\end{array}$ & $\begin{array}{l}\text { Pessoas responsáveis pelos domicílios particulares permanentes - } 10 \text { a } 19 \text { anos de } \\
\text { idade } \\
\text { Pessoas responsáveis pelos domicílios particulares permanentes - } 20 \text { a } 29 \text { anos de } \\
\text { idade } \\
\text { Pessoas responsáveis pelos domicílios particulares permanentes - } 30 \text { a } 39 \text { anos de } \\
\text { idade } \\
\text { Pessoas responsáveis pelos domicílios particulares permanentes - } 40 \text { a } 49 \text { anos de } \\
\text { idade } \\
\text { Pessoas responsáveis pelos domicílios particulares permanentes - } 50 \text { a } 59 \text { anos de } \\
\text { idade } \\
\text { Pessoas responsáveis pelos domicílios particulares permanentes - } 60 \text { a } 69 \text { anos de } \\
\text { idade } \\
\text { Pessoas responsáveis pelos domicílios particulares permanentes - } 70 \text { a } 79 \text { anos de } \\
\text { idade } \\
\text { Pessoas responsáveis pelos domicílios particulares permanentes - } 80 \text { anos de idade ou } \\
\text { mais } \\
\text { Pessoas residentes }-0 \text { anos de idade } \\
\text { Pessoas residentes }-1 \text { anos de idade } \\
\text { Pessoas residentes }-2 \text { anos de idade } \\
\text { Pessoas residentes }-3 \text { anos de idade } \\
\text { Pessoas residentes }-4 \text { anos de idade }\end{array}$ \\
\hline $\begin{array}{c}\text { Educação } \\
\text { (Porcentagem) }\end{array}$ & $\begin{array}{l}\text { Pessoas responsáveis pelos domicílios particulares permanentes - alfabetizadas } \\
\text { Pessoas responsáveis pelos domicílios particulares permanentes - série concluída com } \\
\text { aprovação oitava série - ensino fundamental ou primeiro grau } \\
\text { Anos de estudo - pessoas responsáveis pelos domicílios particulares permanentes }\end{array}$ \\
\hline
\end{tabular}

Fonte: Censo demográfico IBGE, 2000. 
No estudo foram utilizados os 157 setores censitários (2000) pertencentes ao distrito de Cachoeirinha, entretanto, os indicadores relacionados à habitação e saneamento foram elaborados de acordo com a quantidade de domicílios particulares permanentes, pois, todas as demais variáveis selecionadas para compor esses indicadores são referentes a essa variável específica.

\section{Análise Fatorial}

É uma análise multivariada que se aplica à busca de identificação de fatores num conjunto de dados. A redução da dimensionalidade, além do procedimento de processamento de dados para a condução de análises multivariadas, é objeto específico da análise fatorial e da análise de correspondência (Pereira, 2001).

Tabela 3: Indicadores selecionados para a análise fatorial.

\begin{tabular}{|c|c|}
\hline $\begin{array}{c}\text { Condições } \\
\text { de Saneamento }\end{array}$ & $\begin{array}{l}\text { Domicílios particulares permanentes - abastecimento de água - rede geral (\%) } \\
\text { Domicílios particulares permanentes - abastecimento de água - rede geral - } \\
\text { canalizada em pelo menos um cômodo (\%) } \\
\text { Domicílios particulares permanentes - com banheiro ou sanitário - esgotamento } \\
\text { sanitário - } \\
\text { rede geral de esgoto ou pluvial (\%) } \\
\text { Domicílios particulares permanentes - destino do lixo - coletado por serviço de } \\
\text { limpeza (\%) }\end{array}$ \\
\hline $\begin{array}{c}\text { Situação } \\
\text { Socioeconômica }\end{array}$ & $\begin{array}{l}\text { Rendimento nominal médio do responsável pelo domicílio (em Salários Mínimos) } \\
\text { Pessoas responsáveis pelos domicílios particulares permanentes - alfabetizadas (\%) } \\
\text { Pessoas responsáveis pelos domicílios particulares permanentes - série concluída com } \\
\text { aprovação } \\
\text { oitava série - ensino fundamental ou primeiro grau (\%) } \\
\text { Anos de estudo - pessoas responsáveis pelos domicílios particulares permanentes }\end{array}$ \\
\hline Demografia & $\begin{array}{l}\text { Proporção de crianças de } 0 \text { a } 4 \text { anos por setor (\%) } \\
\text { Número médio de habitantes por domicílio }\end{array}$ \\
\hline
\end{tabular}

Fonte: Censo Demográfico IBGE, 2000.

Para a criação de um índice sintético de qualidade de vida, primeiramente foi realizada a análise fatorial com base em variáveis da amostra do Censo Demográfico 2000 IBGE, selecionadas por apresentarem boa interdependência entre si e com os parâmetros propostos para se medir a qualidade de vida.

As variáveis consideradas estão relacionadas a seguir: 
Esses indicadores foram mantidos na amostra, os demais foram excluídos após vários testes, pois dessa forma procurou-se obter os indicadores mais expressivos para cada conjunto, pois, se todos os indicadores expressos na tabela 2 fossem utilizados a análise fatorial teria sido inviabilizada.

Nesse sentido, o índice sintético criado relacionou as três dimensões expostas acima, condições de saneamento, situação socioeconômica e demografia, sendo inserido o número médio de habitantes por domicílio.

A identificação de novas dimensões na análise fatorial foi realizada através do método das componentes principais. Esse não é o único e há alternativas que podem ser consideradas (Maximum likehood, Alpha factoring...).

\section{Análise de Agrupamento (Cluster Analysis)}

É outro tipo de análise multivariada. Nessa análise as distâncias entre os objetos estudados dentro do espaço multpiplano constituído por eixos de todas as variáveis são calculadas e a seguir os objetos são agrupados de acordo com as proximidades entre eles (Pereira, 2001). A análise do tipo cluster pode ser sintetizada de acordo com os seguintes procedimentos:

- Primeiro se realiza o cálculo das distâncias euclidianas entre os objetos estudados no espaço multiplano de todas as variáveis consideradas.

- Seqüência de agrupamento por ordem geométrica

- Reconhecimento dos passos de agrupamento para a identificação coerente de grupos dentro do universo de objetos estudados (Pereira, 2001).

No caso do presente trabalho, foram realizadas duas análises de agrupamento. A primeira agrupou os fatores obtidos na análise fatorial e os desmembrou em quatro grupos. A segunda agrupou os resultados da primeira análise de agrupamento, com a classificação qualitativa das zonas residenciais homogêneas, gerando o mapa síntese (Figura 5).

\section{Interpretação visual da imagem Ikonos}

O mapa de uso do solo foi elaborado por meio de técnicas de interpretação visual de imagens de satélite IKONOS (2002) composição colorida bandas 3, 2, 1, associando-se às cores vermelho $(R)$, verde $(G)$ e azul (B). Para isso, utilizou-se a metodologia consolidada de 
interpretação visual de fotografias aéreas tendo em vista o grau de detalhamento das informações contidas no produto.

A interpretação de imagens enquanto envolve três etapas distintas: a leitura ou reconhecimento, a análise e a fotointerpretação (Souza, 2004).

A leitura ou reconhecimento enquanto método consiste na interpretação preliminar, um reconhecimento inicial de feições presentes nas imagens. A leitura exige conhecimento técnico e experiência do intérprete. É nesta etapa que as feições e os objetos são identificados e ordenados de acordo com o contexto inserido.

A etapa final é a fotointerpretação propriamente dita, esta é a fase em que a interpretação exige os raciocínios lógicos, dedutivo e indutivo do intérprete para explicar objetos identificados nas etapas anteriores.

\section{Determinação das zonas residenciais homogêneas}

Após a definição do mapa de uso do solo, foram delimitadas as zonas residenciais e caracterizada diferentes texturas para estas classes. Este procedimento foi executado no formato digital na tela do computador e verificado em campo, pois algumas variáveis não foram possíveis de serem detectadas na imagem.

A determinação das zonas residenciais homogêneas seguiu os mesmos parâmetros estabelecidos por Kurkdjian (1986) e Souza (2004), que adotaram uma metodologia de setorização residencial urbana, baseando-se na discriminação visual da textura de imagens e satélites IKONOS II e fotografias aéreas pancromáticas 1:10.000, respectivamente.

Dentre as variáveis físicas interpretadas nesta fase de análise, foram destacadas as consideradas abaixo e que são passíveis de verificação a partir dos produtos digitais utilizados.

- Arborização de logradouros e lotes

Verificou-se presença de jardins e ruas arborizadas, geralmente preocupação vinculada à população com um bom poder aquisitivo.

\section{- Tamanho e ocupação do Lote}

Essas variáveis estão fortemente vinculadas à renda familiar, as disposições das construções e seus tipos, se possuem piscinas, tamanho dos telhados e tipos de telhados. 


\section{- Organização das quadras}

Permite a diferenciação das áreas planejadas e regulamentadas daqueles onde a ocupação ocorreu ao longo dos anos sem planejamento e que possuem formas e tamanhos variados das construções residenciais.

- Traçado e tratamento do sistema viário

Permite a identificação de ruas mais largas, estreitas, se são pavimentadas ou não e também se os traçados são regulares.

De acordo com as características acima descritas, foram determinadas 11 Zonas residenciais homogêneas expostas a seguir:

\section{Zona Residencial Homogênea 1 - ZRH 1}

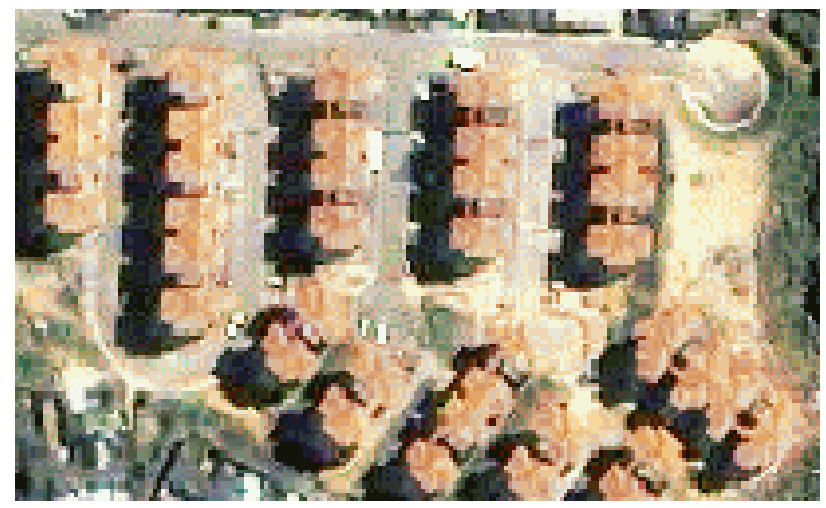

Esta Zona é formada pelo Conjunto Habitacional de Vila Nova Cachoeirinha denominada COHAB VILA NOVA CACHOEIRINHA. O conjunto localiza-se em uma área urbana dotada de infraestrutura e de ocupação consolidada. O conjunto é rodeado pela favela Morro da Esperança, o traçado viário é regular e algumas ruas apresentam pavimentação. Praticamente não apresenta arborização, sendo as áreas verdes do em torno representativa devido à proximidade do Conjunto ao Cemitério de Cachoeirinha.

Zona Residencial Homogênea 2 - ZRH 2

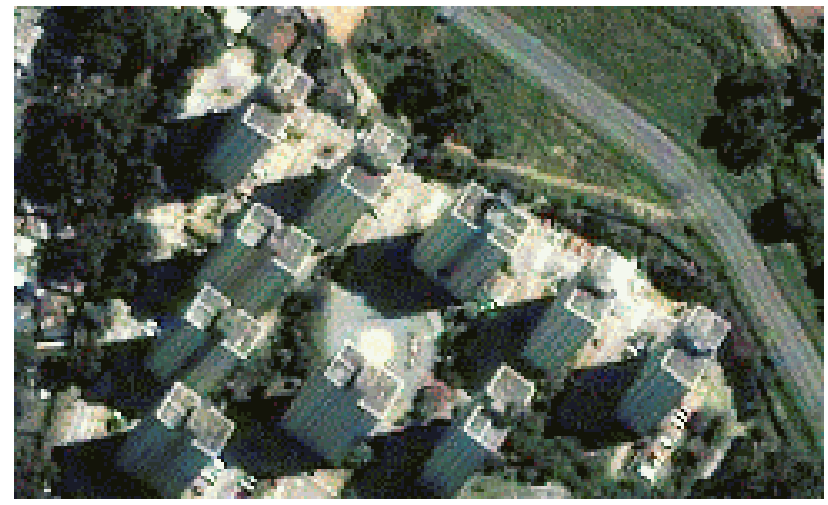


Esta zona é formada por um condomínio de edifícios. O condomínio está localizado em uma região urbana consolidada e dotado de infraestrutura, fica bem próximo da Serra da Cantareira. Ao lado do condomínio localiza-se a favela Eucaliptos II. O sistema viário da zona é regular e as ruas são pavimentadas. Apresenta considerável arborização e inclusive uma praça no centro do conjunto. Apresenta edifícios com mais de 10 pavimentos, porém não há áreas de lazer conforme os edifícios da ZRH 10.

Zona Residencial Homogênea 3 - ZRH 3

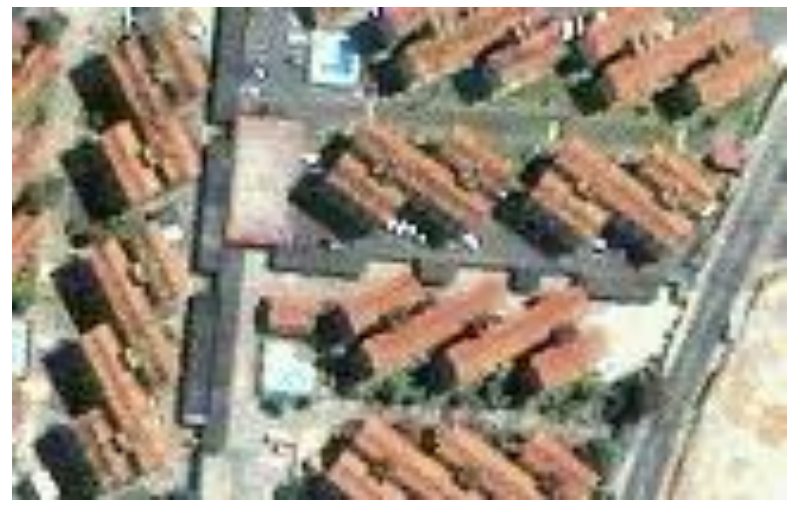

Esta zona residencial é formada também por conjunto de edifícios, entretanto, sua particularidade se encontra na área de lazer, composta por piscinas (pelo menos três foram identificadas), quadras de esporte e campo de futebol. A presença de arborização na área não é notável, porém a presença de jardins demonstra ter havido um planejamento ou até mesmo um projeto paisagístico para esses conjuntos de edifícios. Esse conjunto residencial localiza-se na Avenida Inajar de Souza, esquina com a rua Pedro D’oro.

Zona Residencial Homogênea 4 - ZRH 4

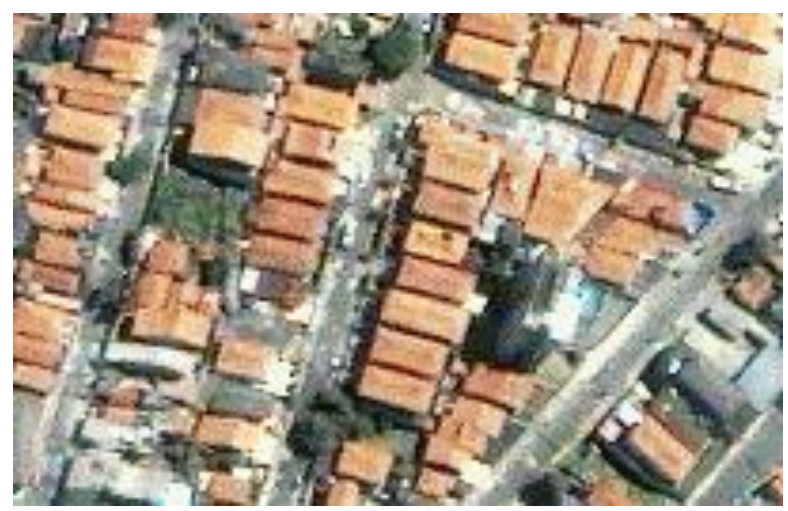

Esta Zona se caracteriza por apresentar lotes urbanos grandes (maiores de $300 \mathrm{~m}^{2}$ ), com a presença de residências unifamiliares, texturas parecidas, tamanhos dos telhados também semelhantes e as cores que demonstram serem construídos de cerâmica. Alguns lotes 
apresentam piscinas. O sistema viário é regular, as ruas são pavimentadas e seu entorno é bem arborizado.

Zona Residencial Homogênea 5 - ZRH 5

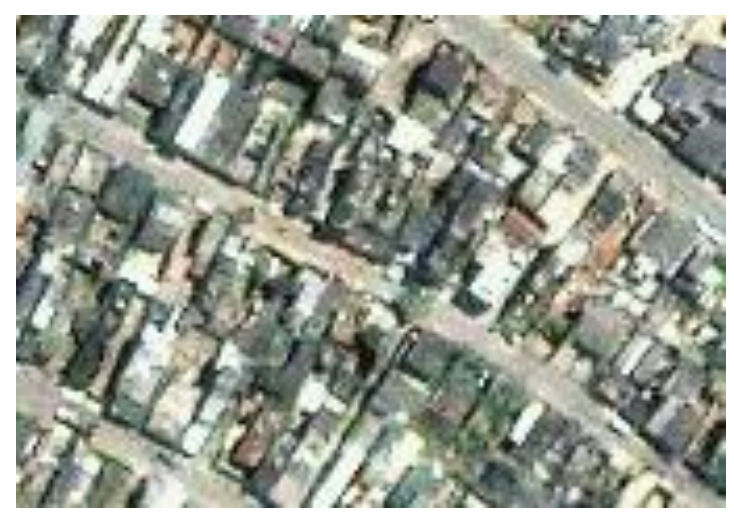

Esta zona residencial apresenta lotes bem menores que a anterior, não há praticamente a presença de telhados de cerâmica, as casas possuem laje ou telhado de amianto. As residências são horizontais e praticamente são todas auto-construídas, a laje caracteriza a idéia da possível criação de mais um pavimento. As casas dessa zona residencial podem chegar a até quatro andares.

Praticamente não existe arborização nas ruas nem nos lotes, tomados pela construção inteira. A ocupação é consolidada, as ruas são pavimentadas, mas não aparenta possuir boa infraestrutura. Essa zona é rodeada de favelas que beiram a Serra da Cantareira.

Zona Residencial Homogênea 6-ZRH 6

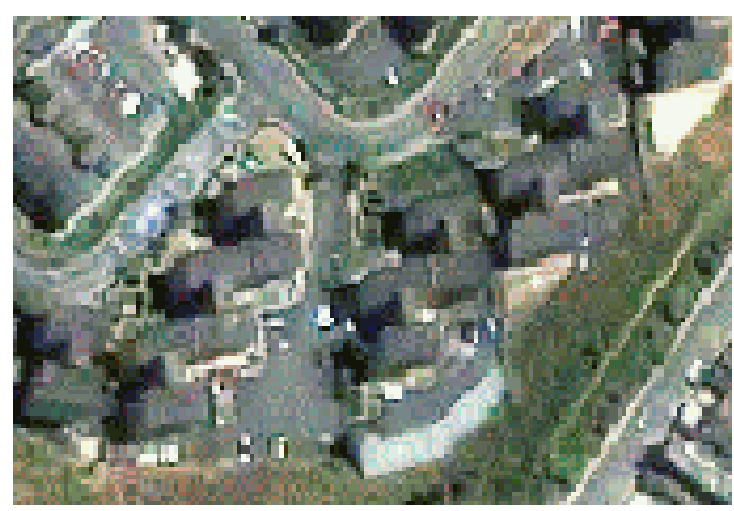

Esta zona residencial é composta por conjuntos habitacionais verticais que apresentam texturas próximas. O traçado viário da área é regular e as ruas são pavimentadas. Apesar dos conjuntos estarem localizados bem próximos a Serra da Cantareira, eles praticamente não apresentam arborização. O Conjunto habitacional Jardim Antártica, é um desses conjuntos. Zona Residencial Homogênea 7-ZRH 7 


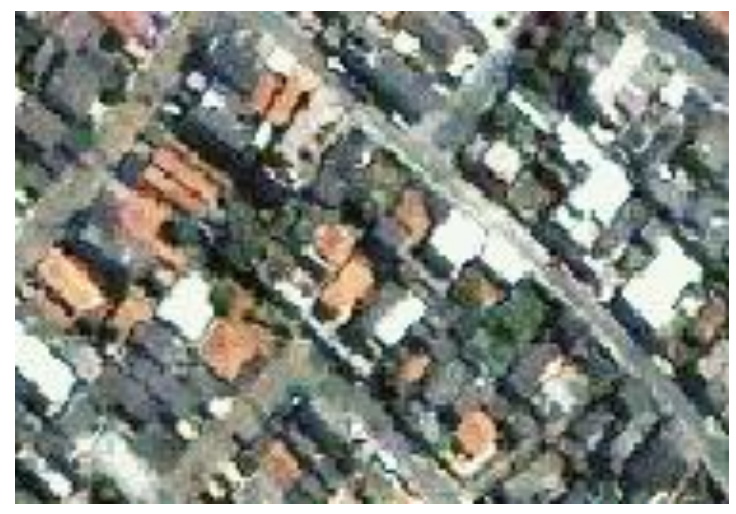

Esta zona residencial é formada por texturas mescladas de casas com telhados de cerâmica e lajes. Os lotes também possuem tamanhos aproximados. Há uma divisão melhor dos lotes do que a divisão observada na imagem de satélite. Existe boa infraestrutura, no entanto, nas ruas existem casas tanto com telhado cerâmico quanto amianto.

\section{Zona Residencial Homogênea 8-ZRH 8}

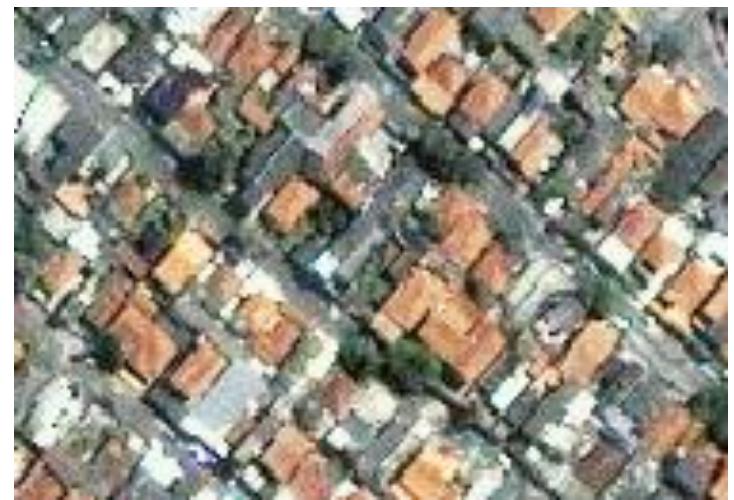

Esta zona apresenta lotes urbanos com um tamanho razoável (250 a $300 \mathrm{~m}^{2}$ ), um pouco menor do que os lotes da ZRH 4. As ruas desta zona apresentam-se arborizadas. $\mathrm{O}$ traçado viário é regular, a área urbana é consolidada e apresenta boa infra-estrutura.

As casas desta zona apresentam predominantemente telhado de cerâmica.

\section{Zona Residencial Homogênea 9-ZRH 9}

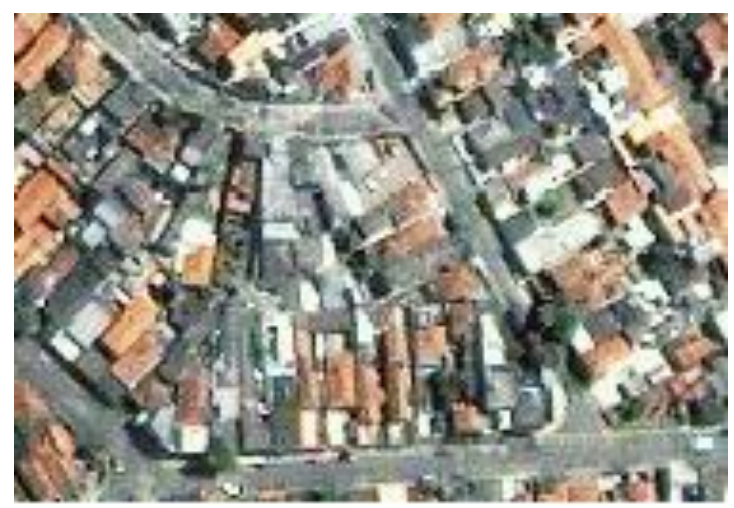


Esta zona apresenta grande densidade construtiva, traçado viário regular, ruas pavimentadas. Seus lotes são pequenos, igual ou menor a $125 \mathrm{~m}^{2}$, de onde se observa a grande densidade. Essa zona residencial é composta principalmente por casas com telhado cerâmico e a arborização é menor do que na ZRH 8 e a densidade é maior.

Zona Residencial Homogênea 10 - ZRH 10

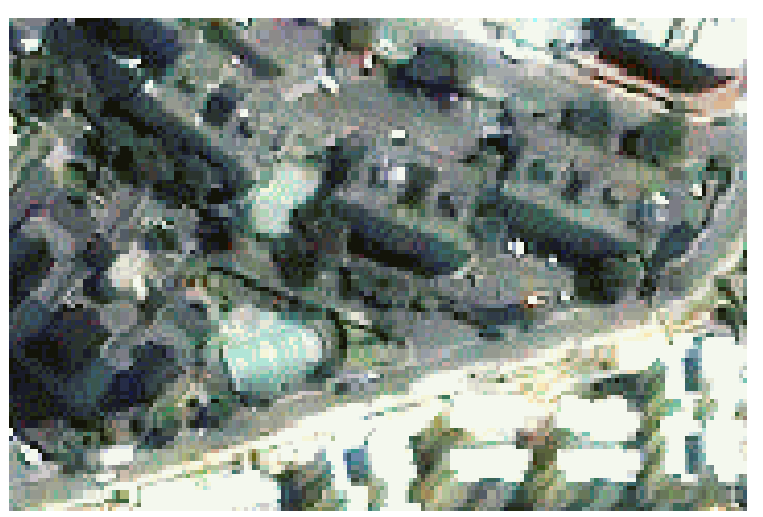

Esta zona residencial é formada por edifícios com mais de 10 pavimentos. Esses edifícios possuem ampla área de lazer e jardins planejados. Atendem principalmente à classe média. Essa zona aparece espalhada pelo distrito de cachoeirinha, mas não é muito representativa, pois a área de estudo é principalmente composta por residências horizontais.

Zona Residencial Homogênea 11 - ZRH 11 - Favelas

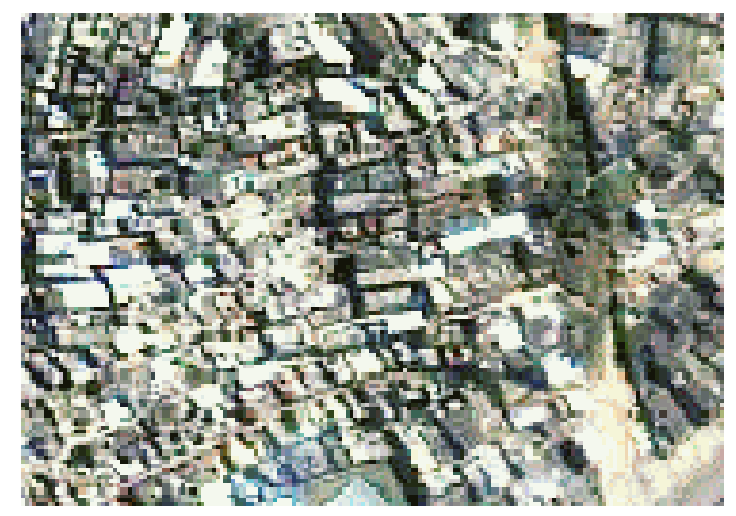

Esta zona apresenta traçado viário irregular, onde muitas ruas não são pavimentadas. É possível observar que os lotes não são definidos e não existem recuos. O tipo de telhado predominante são as lajes e telha amianto. As unidades residenciais são construídas em alvenaria sem acabamento externo, alguns são barracos, conforma a foto abaixo na beira do córrego do Bispo. 


\section{Análise de agrupamento final}

Após a elaboração da primeira análise estatística baseada nos dados do Censo Demográfico 2000 (IBGE) e do mapa das zonas residenciais homogêneas, por meio de interpretação das imagens de satélites, elaborou-se uma classificação qualitativa dessas zonas. Essa classificação norteou o processo de fusão dos dados dos setores censitários e das zonas residenciais homogêneas.

Essa classificação foi baseada na divisão das zonas residenciais homogêneas em quatro classes, de acordo com as qualidades observadas nas categorias de cada zona conforme exposto abaixo:

- $\quad \mathrm{ZRH} 4, \mathrm{ZRH} 8, \mathrm{ZRH} 9-$ Boa

- ZRH 1, ZRH 2, ZRH 3, ZRH 6, ZRH 10 - Razoável

- ZRH 5-Ruim

- FAVELA - Péssima

Os dados classificados acima foram numerados para posteriormente serem processados:

- $\mathrm{BOA}-1$

- RAZOÁVEL - 2

- RUIM-3

- PÉSSIMA - 4

No processo de imputação dos dados processados no software SPSS para o SIG, foram utilizadas ferramentas existentes no sistema que permitem a migração de um banco de dados espaciais para outro por meio da função join, que permite a migração de dados processados fora do SIG, mas que contenha a mesma chave primária, que no caso é numeração dos setores censitários.

Após a imputação dos dados no SIG e da classificação dos dados qualitativos, foi efetuada outra análise de agrupamento, visando agregar os dados obtidos via setores censitários e dados das zonas residenciais homogêneas. Para isso, foi utlizada a função overlay do SIG que trabalha essencialmente com a lógica da sobreposição de áreas (SOUZA, 2006). 


\section{RESULTADOS}

De acordo com o mapa de Uso do Solo e Cobertura vegetal (2002), é possível observarmos a distribuição de favelas na porção urbana ao norte do distrito, acompanhado por alguns conjuntos habitacionais, bem próximos ao limite do parque estadual da Cantareira.

A chave de interpretação consiste na descrição do conjunto de elementos verificados na fotointerpretação, de modo a caracterizar o alvo da superfície terrestre. Um dos tipos mais comuns das chaves de interpretação é o que apresenta uma descrição dos objetos de acordo com sua aparência e ocorrência no terreno.

Devido à importância das áreas residenciais para a realização da presente pesquisa, deu-se um enfoque maior nas zonas residenciais, de onde foram reconhecidas as seguintes categorias:

Cemitério - Geralmente é considerada como área institucional, entretanto, devido à escala de trabalho, essa área é facilmente identificada na imagem e apresenta textura bastante rugosa, forma e tamanho que o diferenciam dos demais alvos.

Solo Exposto - São áreas claras, onde se é possível detectar a remoção da vegetação e possui uma cor bege bem característica. Geralmente essa categoria representa os terrenos vagos na cidade ou algum empreendimento em implantação.

Campo de Futebol - Nesse distrito a ocupação para fins residênciais é muito grande, os campos de futebol aparecem próximos às favelas e conjuntos habitacionais.

Conjunto Habitacional Vertical - Essas áreas são bastante distinguíveis na área de estudo devido ao padrão dos edifícios, geralmente todos seguem o mesmo padrão construtivo, tamanho das edificações e dos lotes. A textura é bastante variada e diferenciada de acordo com o tipo, tamanho e outras variáveis associadas. Nas zonas residenciais essa chave será analisada mais detalhadamente.

Capoeira - São áreas verdes que foram desmatadas e apresentam apenas algumas árvores de baixo porte e grama. São representados por algumas áreas públicas ou terrenos vagos.

Mata - É a mata preservada que se encontra no parque estadual da Cantareira ao norte da área de estudo.

Favelas - São áreas onde se localizam as residências mais precárias do distrito. Possuem uma textura rugosa, onde dificilmente se verifica o tamanho do lote, as 
ruas também possuem um traçado irregular. As casas possuem uma cobertura cinza ou acinzentada representada pelas telhas de amianto ou por lajes.

Residências Horizontais - Essas áreas foram bem distinguidas na área de estudo. Há a presença de arruamento bem definidos, terrenos regulares, predominância da cor laranja no telhado, associada ao material cerâmico. A diferenciação mais detalhada desta área também será realizada no mapa das zonas residenciais homogêneas.

Edifícios - Os edifícios foram identificados na imagem por meio da forma, tamanho e da sombra projetada na imagem.

Galpão - Essas áreas são facilmente identificáveis na imagem, geralmente são edificações grandes e possuem telhados de alumínio que refletem bastante. Em alguns galpões é possível observar pátio de estacionamento. Esta classe foi mais discriminada pelos elementos forma e tamanho.

Equipamento Urbano - Nesta categoria foram considerados shopping centers, terminal de ônibus, escolas, hospitais, igrejas e outras edificações que não entrariam em nenhuma das categorias anteriores. Muitas áreas pertencentes a esta classe foram identificadas por meio do conhecimento que o fotointerprete possui da área de estudo.

Tentou-se efetuar a classificação supervisionada dos usos da área de estudo, mas, por se tratar de uma área urbana densa, a confusão de pixels com as classes criadas foi grande, pois, o software confundiu piscinas com o telhado do terminal de ônibus e telhados dos galpões com lajes.

A classificação das zonas residenciais homogêneas resultou em onze classes interpretativas, de acordo com as chaves de interpretação e o tipo de zona residencial representada. As estatísticas multivariadas por meio da análise fatorial e dos agrupamentos coincidiram com resultados da fotointerpretação das $\mathrm{ZRH}^{\prime} \mathrm{s}$, destacando principalmente as áreas que apresentam baixos indicadores e conseqüentemente baixa qualidade de vida. 


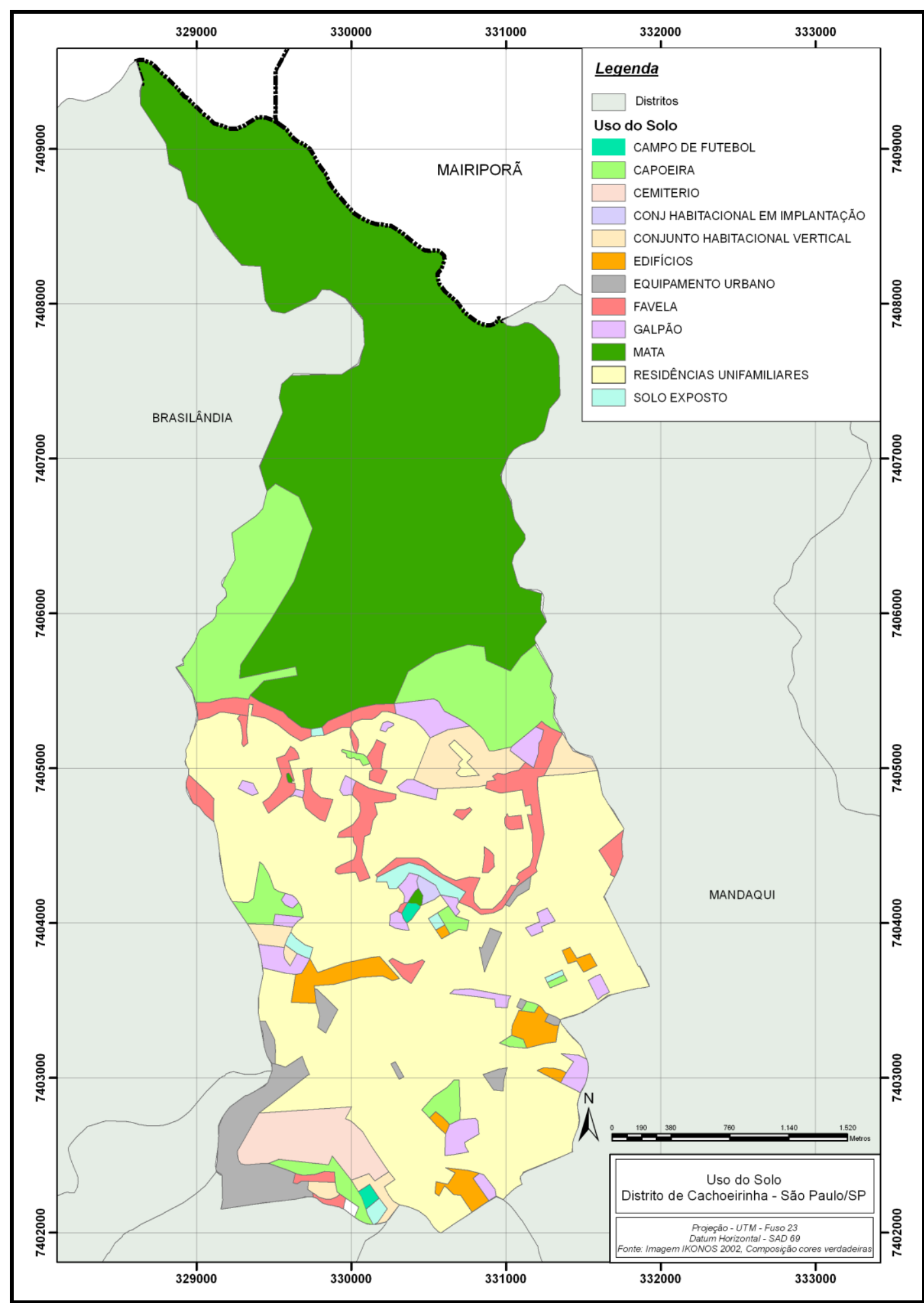

Figura 2: Uso do Solo e Cobertura Vegetal.

Fonte: Imagem Ikonos composição cores verdadeiras. Geolog, 2000. Elaborado pela autora, 2008. 


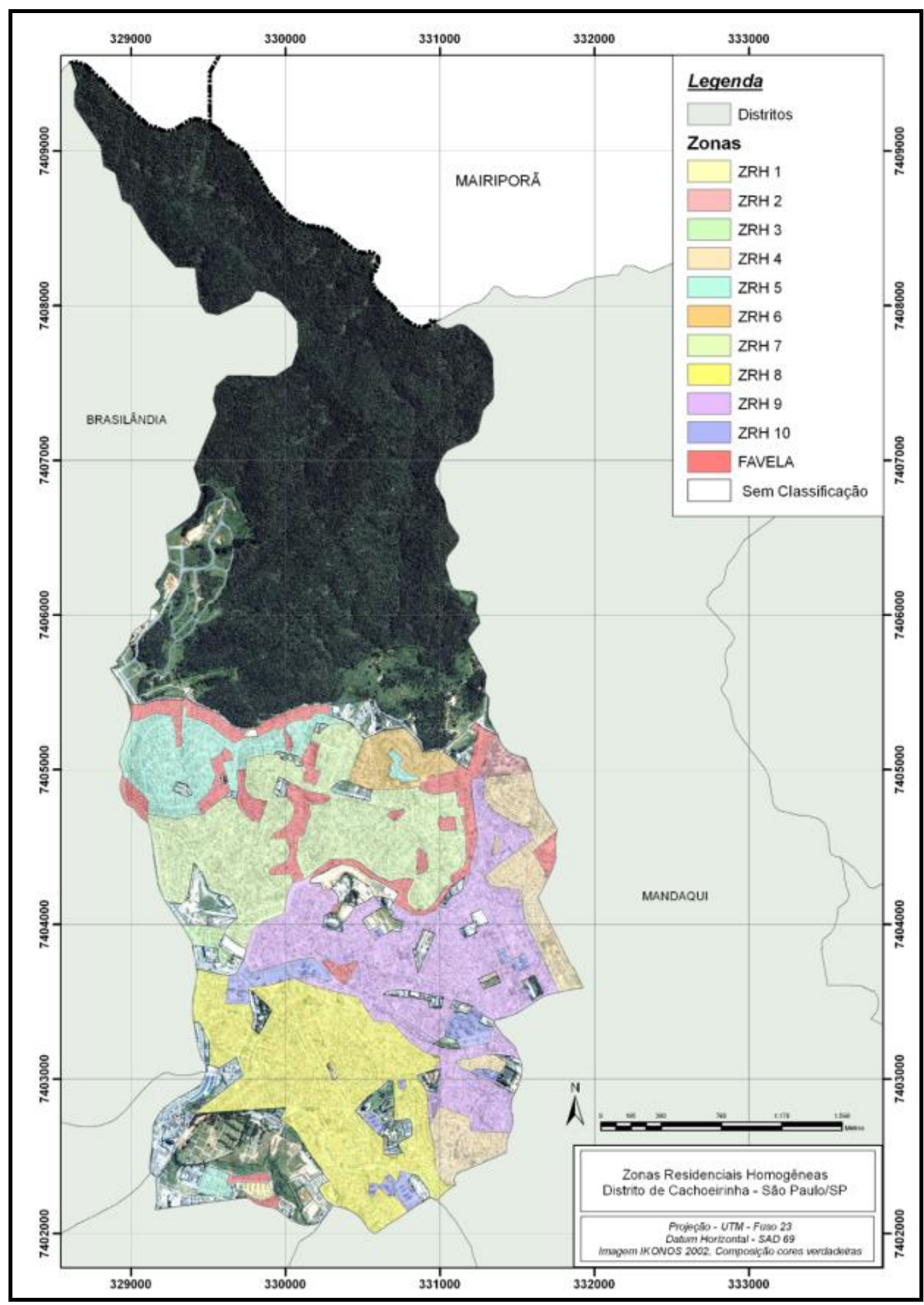

Figura 3: Zonas Residenciais Homogêneas e seus códigos.

Fonte: Imagem Ikonos composição cores verdadeiras. Geolog, 2000. Elaborado pela autora, 2008. 


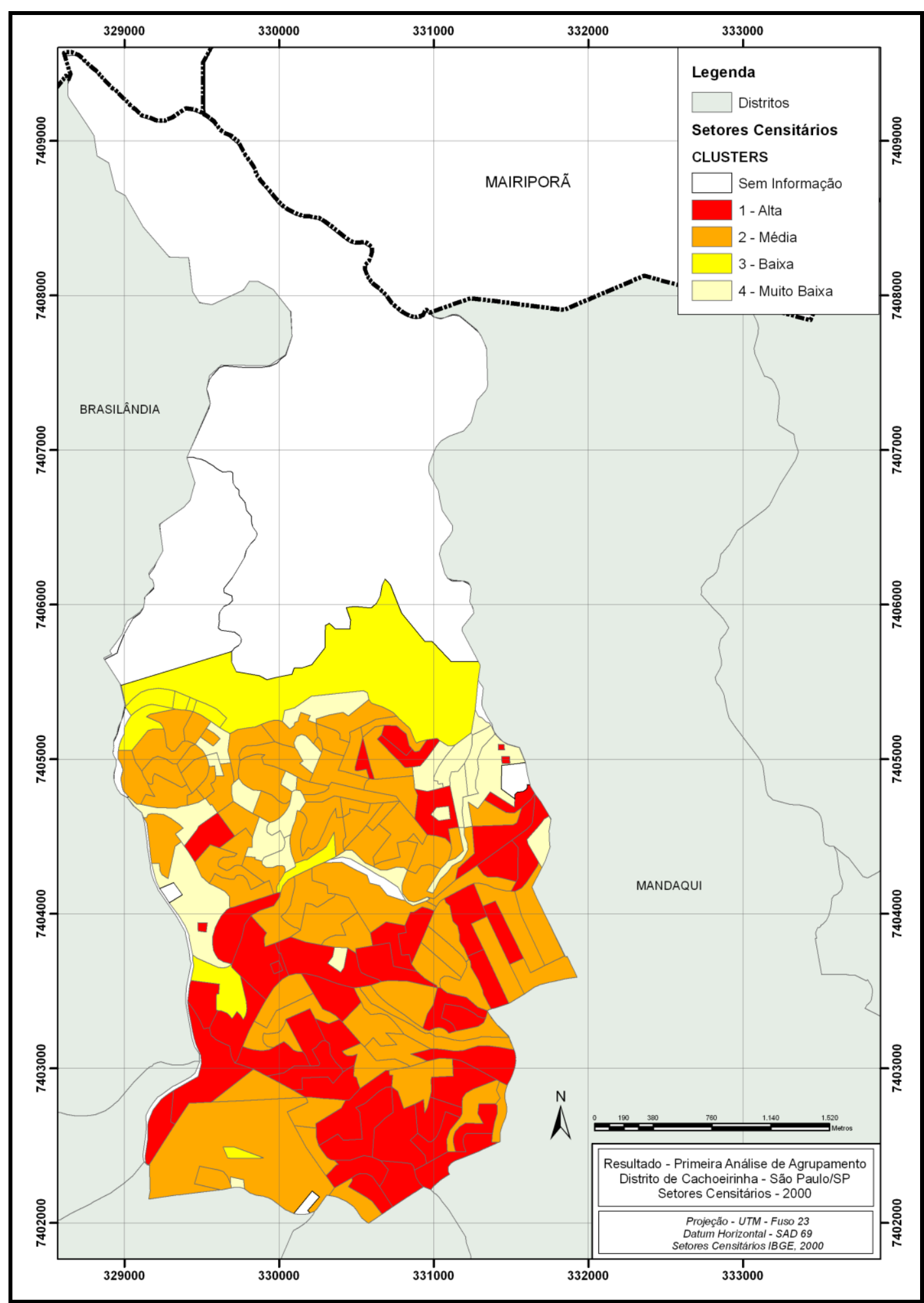

Figura 4: Resultado da primeira análise de agrupamento

Fonte: Setores Censitários IBGE, 2000. CEM/CEBRAP, 2003. Elaborado pela autora, 2008. 


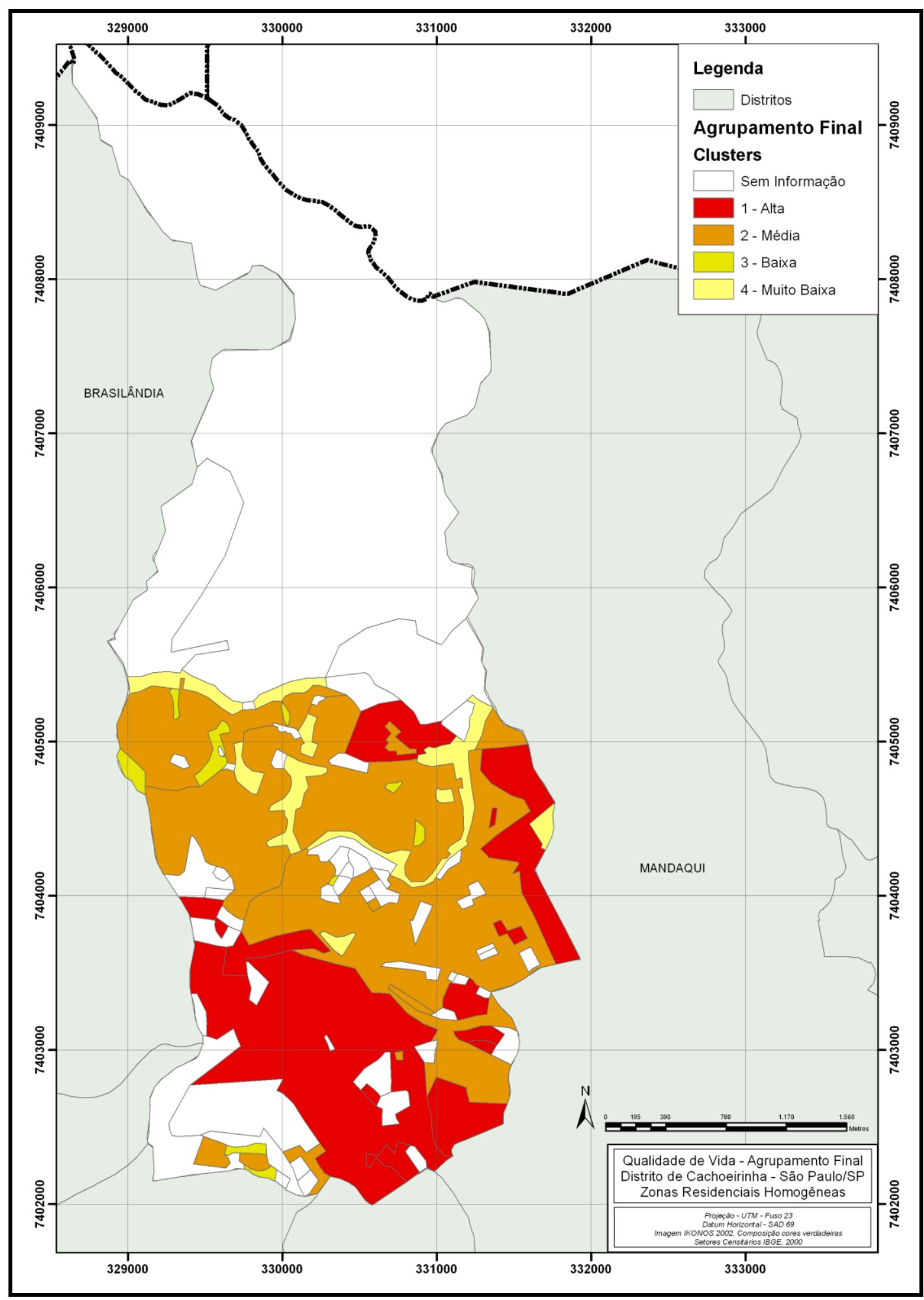

Figura 5: Síntese Final elaborada após as análises multivariadas

Fonte: Síntese Final elaborada após as análises multivariadas. Elaborado pela autora, 2008. 


\section{CONSIDERAÇÕES FINAIS}

Os resultados obtidos no trabalho, de acordo com a fundamentação teórica e a metodologia adotada, demonstraram que a união das técnicas de sensoriamento remoto, cartografia digital e estatísticas multivariadas são adequadas para análise intra-urbana.

A metodologia proposta apresentou bons resultados para análise da qualidade de vida urbana no distrito de Cachoeirinha e ao contrário do que muitas vezes se pensa na ciência Geográfica, o auxílio dos números, ou melhor, das técnicas estatísticas, podem ser grandes aliados na demonstração de resultados de maneira mais objetiva. É certo que a seleção de variáveis pode ser considerada arbitrária, no entanto, se isto ocorresse dessa maneira, os modelos de análises multivariadas propostos, dificilmente estariam adequados e com isso, não seriam encontrados resultados com distribuição espacial coerentes dos fenômenos.

As estatísticas multivariadas, como a análise fatorial e análise de agrupamento elaboradas neste trabalho, também se constituem técnicas já consagradas aplicadas nas Ciências Sociais. A identificação de zonas residenciais homogêneas propiciou uma classificação qualitativa dessas residências, que expressam diferentes tipos de ocupação, planejadas ou não verificadas por meio do tamanho do lote, distribuição da construção, organização das quadras e traçado e tratamento do sistema viário.

O Crescimento concêntrico da cidade também pôde ser observado nos resultados apresentados por meio dos mapas elaborados neste estudo; mas, principalmente, no mapa síntese final, confirmando assim que os estudos de morfologias das cidades muito têm a explicar a respeito da distribuição espacial nas áreas urbanas, e que estes podem auxiliar outras pesquisas relacionadas à segregação espacial bem como à qualidade de vida urbana, como no caso da presente pesquisa.

\section{REFERÊNCIAS BIBLIOGRÁFICAS}

ALMEIDA,C. M. O Diálogo entre as Dimensões Real e Virtual do Urbano. In Geoinformação em urbanismo: cidade real x cidade virtual. São Paulo: Oficina de textos, 2007.

ARCHELA, R. S. A Cartografia no Pensamento Geográfico. Disponível em http://br.geocities.com/cartografiatematica/textos/Pensamen.html Acesso em 13/12/2010. 
CÂMARA, G. \& MONTEIRO, M. \& MEDEIROS J. S. de Representações Computacionais do Espaço: Um diálogo entre a Geografia e a Ciência da Geoinformação. Divisão de Processamento de Imagens Instituto Nacional de Pesquisas Espaciais (DPI/INPE), São José dos Campos: 2000.

CARLOS, Ana Fani A. A (Re)produção do Espaço Urbano. São Paulo:Editora da Universidade de São Paulo, 1994.

CEM/CEBRAP, Censo Demográfico por Setores Censitários IBGE 2000 - Bases de dados com cartografias e variáveis censitárias (dados demográficos, socioeconômicos, caracterização dos domicílios etc.) da Região Metropolitana de São Paulo, 2003.

CÔRREA, Lobato Roberto. O Espaço Urbano. São Paulo: Ática, 2005.

FILHO, O. Bueno Amorim \& FILHO, N. de Sena. A Morfologia das Cidades. Goiânia: Ed. Vieira, 2005.

FLORENZANO, T. Gallotti, Imagens de Satélite para Estudos Ambientais. São Paulo, Oficina de Textos, 2002.

FRÚGOLI JÚNIOR, Heitor. Centralidades em São Paulo: Trajetórias, Conflitos e Negociações na Metrópole. São Paulo: Cortez/Edusp, 2000.

HARVEY, D. Explanation in Geography. Londres, 1969.

GERARDI, L. H. O. \& SILVA, B. C. N. Quantificação em Geografia. São Paulo:Difel, 1981.

JANUZZI, P. M. Indicadores Sociais na formulação e avaliação de Políticas Públicas - Revista Brasileira de Administração Pública, Rio de Janeiro, V. 36 p. 51-72, Janeiro/fevereiro 2002.

KURKDJIAN, M. L. N. O. Um método para a identificação e análise de setores residenciais urbanos homogêneos, através de dados de sensoriamento remoto, com vistas ao planejamento urbano. 1986. 146 páginas. Tese de Doutorado - FAU/USP, São Paulo.

LUCHIARI, A. As Tecnologias para Análise do Espaço. Informe - Informativo da FFLCH/USP, São Paulo, Nova Série, n²5, p.1-4, outubro 2001. 
LUCHIARI \& KAWAKUBO \& MORATO, A. \& F. S. \& R. G \& MARTINES \& FERREIRA A. \& F. S. \&

R. G. \& M. R. \& R. V - Mapeamento da Qualidade de vida Urbana no Município de Osasco/SP. Artigo apresentado no III Encontro da Associação Nacional de Pós Graduação e Pesquisa em Ambiente e Sociedade - Maio, 2006.

MARQUES, E. Elementos Conceituais da Segregação, da pobreza urbana e da ação do Estado. MARQUES \& TORRES, E. \& H. (Orgs.) In São Paulo: Segregação, Pobreza e Desigualdades Sociais. São Paulo:Senac, 2005. (19-56)

MORATO, R. G. Análise da Qualidade de Vida Urbana no Município de Embu/SP. 2004. 108 páginas Dissertação de Mestrado - FFLCH/USP , São Paulo.

NOVO, E. M. L. de Sensoriamento remoto: princípios e aplicações. Sao Paulo: Edgard Blucher, 1989.

NUCCl, J. C. Qualidade Ambiental \& Adensamento Urbano. São Paulo: Humanitas/FFLCH/USP, 2001.

PEREIRA, J. C. R. Análise de dados qualitativos - Estratégias Metodológicas para as Ciências da Saúde, Humanas e Sociais. São Paulo: EDUSP, 2001.

SANTOS, M. Por uma Geografia nova: da crítica da Geografia a uma Geografia crítica. São Paulo: Editora da Universidade de São Paulo, 2002.

SOUZA, Gustavo C. O. Construção de um Indicador Sócioambiental: O exemplo do município de São Paulo. In São Paulo Perspectiva. Fundação SEADE. 2006.

SOUZA, Íris. M. Análise do Espaço Intra-Urbano para Estimativa Populacional Intercensitária Utilizando Dados Orbitais de Alta Resolução. 2004. 87 páginas Dissertação de Mestrado (Mestrado em Planejamento Urbano e Regional) - INPE, São José dos Campos.

TORRES, H. Medindo a Segregação. MARQUES \& TORRES, E. \& H. (Orgs.) In São Paulo: Segregação, Pobreza e Desigualdades Sociais. São Paulo:Senac, 2005. (81-100).

Artigo recebido em 16/08/2011. Artigo aceito em 13/10/2011. 